\title{
IMPLEMENTATION OF THE METHOD OF PROBLEM-BASED LEARNING AT AKAKI TSERETELI STATE UNIVERSITY
}

\author{
Valishvili Tamara \\ Akaki Tsereteli State University, Kutaisi, Georgia \\ Valishvili Tea \\ Akaki Tsereteli State University, Kutaisi, Georgia
}

(C) MESTE NGO

JEL category: D83, I2, I23

\begin{abstract}
The global processes of the modern society dictate new approaches in modern education. Therefore, an education system are made very high demands: it has to prepare the specialists for life and work activity in the quickly changing world, where the person performs non-standard tasks constantly. Use of various new techniques improves the process of studying, teaches the student to think and really to use their knowledge gained at the lectures. In this article we will consider a method of "Problem Based Learning" which promotes deeper understanding of the studied material and application of the gained knowledge in practice. Akaki Tsereteli State University takes an active position in implementation of the modern educational technologies, including the problem-based learning. Now within the university education this method is used at the individual level. New practice is in a traditional framework of the existing educational system, it treats the activity of each individual teacher and so it is very private. At this level changes don't have great influence on the University. In fact, they are carried out so that anybody doesn't know about it, except the involved teacher. The method allows not only to form and fix skills of knowledge acquisition, but also to learn specifics of work in team.
\end{abstract}

Keywords: problem-based learning, education, system approach, education, knowledge

\section{INTRODUCTION}

The global processes of the modern society dictate new approaches to modern education. Therefore, an education system is to meet high demands: it has to prepare the specialists for life

Address of the corresponding author:

Valishvili Tamara

焦Tamriko3@gmail.com and work activity in the quickly changing world, where a person performs non-standard tasks constantly. We live in the modern quickly changing world, where the competition becomes more and more strong every day, and so lack of practical experience and skills of the students can become a serious and essential obstacle on the way to their employment and career growth. In this regard, the increasing popularity is gained by the modern techniques of studying, directed on the 
development the certain practical skills of the students. The correct combination of traditional and innovative methods of studying help students to acquire not only theoretical knowledge (they often have non-systemic, different character), but also promote the development of the practical professional skills.

Use of various new techniques improves the process of studying, teaches the student to think and really to use their knowledge gained at the lectures. In this article we will consider a method of PBL (Problem Based Learning) which promotes deeper understanding of the studied material and application of the gained knowledge in practice. (Hannafin, Land, \& Oliver, 1999)

\section{PROBLEM-BASED LEARNING - AS THE SUCCESSFUL INNOVATIVE METHOD OF STUDYING}

The method PBL is widespread in Europe and America. It took more than 20 years to create the corresponding techniques and the necessary materials. The real embodiment of PBL inclusion in the university programs - began since the $90 \mathrm{~s}$ of the 20th century. This method is successfully used in the medical education. Today more than 80 percent of the medical schools and universities of Great Britain, USA, Canada and Australia apply methodology of problem-based learning. It allows students to adapt quickly on real environment through creation of the hypothetical and virtual situations. (Levin, 2001).

Though initially PBL was introduced as a method of studying of the medical students, it got the great application in other educational programs and today it is considered as the successful innovative method of studying which is based on independent work of the student. In this method the accent of studying is displaced from the teacher to the student, so now the student plays more active role, trying to solve the practical task. This method has had the attraction of making pedagogical sense - it holds out the hope of fostering the application and integration of knowledge, building on previous understanding, and relevance to future professional activities.

While doing PBL students complete a task rather than looking at a specific area of a subject. By completing a task, learners are practicing a range of topic and are learning what they need and when they need. Students work together to prepare their work which they present to the whole class. Teacher needs to provide them with all necessary information to help them work independently and implement their theoretical knowledge into practice.

The different countries and universities have their own specifics of the organization and methodical ensuring for the similar lessons. At the same time there are also some basic general principles: creations of the cases integrated into the educational program, a role and a place of the teacher, the purposes and the tasks of the students, number of the students in a group, the grading system, and the equipment of the classrooms. The main difference of PBL from the traditional methods of studying in small groups is the organization of the lessons (Hallinger, 2005), so the students have to formulate the questions necessary for the solution of cases themselves and then find the appropriate answers to these questions during the process of the search of the relevant information and joint discussion (Simons, Klein, \& Brush, 2004). One thing that does stand out is the enthusiasm of faculty and students however. A small minority of students found the PBL process difficult and given the choice would prefer another learning method. A few tutors prefer to modify tutorials into a seminar format which may be more familiar and comfortable for them. But the majority of students and tutors find that the PBL process is vastly more engaging and stimulating than traditional formats.

The steps of Problem Based Learning often overlap each other.

\section{Identify the problem}

The students read about the problem and discuss it. They can say "diagnosis" right away, but need to be encouraged to think more deeply about all the "why, how, when". (Hallinger, 2005)

\section{Explore pre-existing knowledge}

Clarifying terms and the meaning of terms used in the problem is a good way to start this step, before going on to a more in depth exploration. Students come with an existing knowledge base and many life experiences. We know that people retain newly acquired knowledge more easily when they already 
know something about it - and this second step allows students to consciously access their own prior understanding and begin to apply it for their own benefit and that of others in the group. Tutors need to ensure that all students participate in this step, and to help the group consider critically the information that is brought forward by its members.

\section{Generate hypotheses and possible mechanisms}

Based on the previous discussion, students generate their different hypotheses about the problem, including possible mechanisms. It is important for the tutor to help them from falling into the trap of jumping to diagnosis and superficial assessment of the clinical aspects of the problem. The goal is to have the students focus on understanding the key concepts which are illustrated by each problem, and this requires that they are deeper into it. The tutor will ensure that all students are engaged in the process of discussion.

\section{Identify learning issues}

Leaning objectives (LOB) may be defined as questions that cannot be answered with current knowledge in the group. At this point, it will have become clear to students what their learning issues are, both as a group and as individuals. These questions will be the basis of the students' search for resources and information, and much frustration can be avoided if they are well formatted and clear. At the end of the problem, the students will need to identify and understand the important concepts contained in the problem, and this should be reflected in the identified issues.

\section{Self-study}

Students have a set amount of time for selfstudy before returning to the next tutorial. It is clear that the educational program design builds in time for this crucial step in the process, and not over schedule the students.

\section{Re-evaluations and application of new} knowledge to the problem

This step of PBL process occurs when the group reconvenes, having spent time learning about the issues identified earlier. It is at this time that the new knowledge and understanding is applied to the original problem, and the tutor is handed the challenge of ensuring that the students are actively engaged and working with their new knowledge. Educational research, as well as common sense suggests that working with new information, questioning it, and applying it to different situations helps stimulate recall for the future. It is important it avoid a series of "mini-lectures" - from each student (or the tutor). Tutors may also stimulate the students rearning by posing questions which challenge them to apply these concepts in slightly different contexts.

\section{Assessment on learning}

Before the Health care Problem and the tutorial can be considered complete, it is important that each student and the group have an opportunity to reflect on the process of learning that has taken place. This includes a review of the learning achieved, but also a chance for group members to give each other feedback about contributions to learning and group process, and an evaluation of how the is working together.

Research suggests that effective use of problembased learning methods can prepare students to be flexible thinkers who can work productively with others to solve problems (Hmelo-Silver, 2004). Moreover, the PBL method has been demonstrated to increase different types of problem-solving skills in students, from describing specific processes needed to address a particular problem, to increasing the depth and breadth of solutions (Dochy, Segers, Van de Bossche, \& Gijbels, 2003). Research also suggests that PBL can help students develop self-directed learning skills and positive attitudes toward learning.

Despite evidence that PBL is a powerful approach, adoption of this method is not as widespread as might be hoped. Like other innovations, PBL poses numerous difficulties for both teachers and students.

Some studies with medical students reflected the same kind of student difficulty in applying knowledge. He observed that medical students often used basic science knowledge incorrectly or not at all in formulating and revising clinical 
diagnoses. When these students became practicing clinicians, some of them rarely knew how to apply learned theoretical knowledge to novel clinical situations.

One prominent explanation to account for this type of student behavior stems from the different views of knowledge and the ways of teaching. In the traditional perspective, declarative knowledge, which refers to content knowledge accrued from research, is taught separately from practice to students in lectures. This perspective on teaching and learning emphasizes the passive nature of the mind where students accumulate knowledge provided by the teacher. Thus, knowledge is detached from the actual real life context, and learners may find it difficult to apply it to novel problem situations.

The aim of education is to get students to develop the functioning knowledge which allows them to integrate academic knowledge base (declarative knowledge), skills required for that profession (procedural knowledge) and the context for using them to solve problems (conditional knowledge). In order to acquire this integration to achieve the aim of education, the traditional way of teaching and learning has to be put aside. Problem-Based Learning $(\mathrm{PBL})$ by its sole nature requires a different way of using knowledge to solve problems. The development of this functioning knowledge is the aim of education in general, and higher education in particular.

The positive effect of PBL on student learning has been well documented, but the weakest link appears to be the assessment methods Teaching and learning operate within a system consisting of the three central components of course objectives, teaching and assessment (Hmelo-Silver, 2004). To facilitate desirable learning outcomes, these three components have to be appropriately aligned. In relation to this, there has been a growing volume of literature looking into the effect of inappropriate assessment on learning in PBLbased courses. When PBL was implemented within a traditional assessment system, most students felt insecure with the PBL approach. The examination results were poor and the course evaluation questionnaire indicated quite a low score on most of the items. On the other hand, if assessment is constructively aligned with the aims and philosophy of $\mathrm{PBL}$, quite a different picture emerged. Findings of this study indicate that students in the PBL class scored higher in the portfolio component of than the non-portfolio component, and the different approaches students used in preparing portfolios were aligned with the aims of PBL (Brinkerhoff \& Glazewski, 2004).

\section{EXPERIENCE WITH AN IMPLEMENTATION OF THE METHOD OF PBL AT ATSU}

Today universities in Georgia conduct researches as a result of which educational changes are initiated to conform to requirements of modern economy and society. These changes cause the development not only professional, but also the personal skills of the students, first of all their ability to the independent studying, including lifelong learning.

Akaki Tsereteli State University takes an active part in implementation of the modern educational techniques including the problem-based learning. Now within the university educational system this method is used at the individual level. New practice has become a part of a traditional framework of the existing system dealt by teachers individually (Kolodner et al., 2003). At this level changes don't have great influence on the University. In fact, they are carried out so that not everybody knows about it, except the involved teacher.

The following level is systemic. This level is characterized by changes in the course or the program, so this means - changes in the teaching and studying methods and in the systems of the grading. The changes don't happen entirely. For the purpose of successful implementation of the innovative methods of studying in the university were developed the special training courses for the teachers. At this moment the new educational program based on the PBL method is created on the basis of the faculty of health care of the university. This program is created as a part of the research project entitle "Establishment of the Supra-Regional Network of the National Centers in Medical Education, focused on PBL (ProblemBased Learning) and Virtual Patients" funded by the European Commission through the Tempus program. (Tempus, 2014) This program includes the specialized computer program for the students, allowing to imitate appropriate clinical 
situation and essentially to increase efficiency of PBL.

The last and highest level is the institutional level. At this level influence on the organization, and also on the students, on the teachers is absolute. It can be described by the following characteristics:

- Students take active part in educational process;

- Studying is cross-disciplinary (interdisciplinary);

- There are changes in the organization and organizational culture;

- There are changes in a format of carrying out examination (control);

- There are changes in methods and the assessment purposes.

At this level the university changes the existing approaches to teaching and management. It is impossible to reach this situation by means of executive decision in very short period, and therefore, implementation of the program takes years.

Achievement of the institutional level is one of the priority directions of the strategic development of the university now.

In our opinion, one of the main advantages PBL is the high motivation of the students to getting new knowledge during such educational process.

The Akaki Tsereteli State University (Georgia) has a teaching development grant to promote and support PBL in health-science curricula. As a result, a PBL team of university consisting of academic staff was formed in 2013. Under the management and coordination of this team, research funding to develop and implement PBL in their respective curricula. To evaluate the effectiveness of PBL implementation, two projects focusing on student learning and faculty perceptions were operated by the PBL consortium team. This paper reports the findings of the latter project on faculty perceptions.

The questionnaire consisted of a demographic section which aimed to identify the culture of institutions (PBL or non-PBL), the academic rank, and the teaching and PBL experience of the respondents. Findings from this section indicated that there were approximately equal numbers of respondents from PBL and non-PBL institutions.
Of these participants, about $40 \%$ were at the rank of senior lecturers or above, and the rest were lecturers/Assistant Professors. $30 \%$ of the respondents had a tertiary teaching experience of over 5 years but only $10 \%$ of them had experience with PBL.

In order to analyze the questionnaire data from the various perspectives, the demographic data set was used to stratify the respondents into different groups: academic rank of the respondents, and their experience with PBL.

The differential analysis of the results of the questionnaire indicates that there are four factors affecting the implementation of PBL in institutions. These factors are, namely, resource, quality assurance, student factor and teaching conception of faculty members. Analysis shows that PBL and non-PBL based institutions differ mainly in the type of support provided for the PBL innovation, namely, full continuous departmental support in the former, and ad hoc research funding support in the latter. In terms of the difference of viewpoints between faculty members of different academic ranking, the senior lecturer group indicated that the teaching conception and quality assurance evaluation system affected the implementation of PBL, whilst the lecturer group indicated that the external student factor played an important role in the successful implementation of PBL. Irrespective of the experience of PBL tutors, all agreed that the quality assurance evaluation mechanism, student factor and teaching belief played an important part in PBL implementation (Lehman, Ertmer, Keck, \& Steele, 2001).

However, those faculty members with less experience in PBL found it quite difficult to take up the PBL teaching approach and they believed that it was impossible to run PBL as an individual course. To sum up, the questionnaire, which was designed from the themes emerged from the interviews conducted in the early phase of this study, confirmed that student factor, teaching conception, and qualitative assurance and/or resource support were the basic hurdles affecting PBL implementation.

The method allows not only to form and fix skills of knowledge acquisition, but also to learn specifics of work in team. Important advantage of PBL is development of abilities of the orientation in interdisciplinary situations and ability to find and 
process a necessary material by means of use of various information sources (lectures, textbooks, dictionaries and reference books, Internet sources and others).

Because the volume of direct instructions at PBL is minimized, students assume the big responsibility for own studying. It is considered that exactly it, and also studying in a context of a real situation allows them to acquire better a material and to make competent and right decisions.

\section{CONCLUSIONS}

The European Union pays today considerable attention to development of this direction. In this article is considered the experience of the realization of PBL based on system approach of the foreign universities. Advantages of this approach in the studying process of bachelors and masters in higher education institutions are shown. Use of these technologies allows forming both professional and personal competences of graduates of educational programs. The analysis allows predicting more widespread introduction of these technologies of studying in higher education institutions of Georgia.

Thus, PBL is the methodology of teaching based on special pedagogical strategy. The method allows to acquire materials through understanding of real life situations that provides full development of materials by students by means of collecting and studying necessary (individual for everyone) information and to create possibilities to develop the skills of team work and concrete decision making.

\section{WORKS CITED}

Brinkerhoff, J., \& Glazewski, K. (2004). Support of expert and novice teachers within a technology enhanced problem-based learning unit: A case study. International Journal of Learning Technology, 1, 219-230.

Dochy, F., Segers, M., Van den Bossche, P., \& Gijbels, D. (2003). Effects of problem-based learning: a meta-analysis. Learning and Instruction, 13, 533-568.

Hallinger, P. (2005, April). Integrating learning technology and problem-based learning: A framework and case study. Paper presented at the annual meeting of the American Educational Research Association, Montreal.

Hmelo-Silver, C. E. (2004). Problem-based learning: What and how do students learn? Educational Psychology Review, 16, 235-266.

Kolodner, J. L., Camp, P. J. Crismond, D., Fasse, J. G., Holbrook, J., Puntambekar, S., \& Ryan, M. (2003). Problem-based learning meets case-based reasoning in the middle Scaffolding Teachers' Efforts to Implement Problem-Based Learning school science classroom: Putting learning by design into practice. Journal of the Learning Sciences, 12, 495-547.

Lehman, J. D., Ertmer, P. A., Keck, K., \& Steele, K. (2001, March). In-service teacher development for fostering problem-based integration of technology. SITE (Society for Information Technology and Teacher Education) 2001 Conference Proceedings. Charlottesville, VA: Association for the Advancement of Computing in Education.

Levin, B. B. (Ed.). (2001). Energizing teacher education and professional development with problembased learning. Alexandria, VA: Association for Supervision and Curriculum Development.

Simons, K. D., Klein, J. D., \& Brush, T. R. (2004). Instructional strategies utilized during the implementation of a hypermedia, problem-based learning environment: A case study. Journal of Interactive Learning Research, 15, 213-233.

Tempus. (2014). Establishment of the Supra-Regional Network of the National Centres in Medical Education, focused on PBL and Virtual Patients. Retrieved from ePBLnet: http://www.epblnet.eu/

Received for publication:

Revision received:

Accepted for publication:
31.01 .2014

12.04.2014

03.06.2014 
How to cite this article?

Style - APA Sixth Edition

Valishvili, T., \& Valishvili, T. (2014, 07 15). Implementation of the method of problem-based learning at Akaki Tsereteli State University. (Z. Čekerevac, Ed.) MEST Journal, 2(2), 251-257. doi:10.12709/mest.02.02.02.25

Style - Chicago Fifteenth Edition:

Valishvili, Tamara, and Tea Valishvili. 2014. "Implementation of the method of problem-based learning at Akaki Tsereteli State University." Edited by Zoran Čekerevac. MEST Journal (MESTE) 2 (2): 251-257. doi:10.12709/mest.02.02.02.25.

Style - GOST Name Sort:

Valishvili Tamara and Valishvili Tea Implementation of the method of problem-based learning at Akaki Tsereteli State University [Journal] // MEST Journal / ed. Čekerevac Zoran. - Belgrade : MESTE, 07 15, 2014. - 2 : Vol. 2. - pp. 251-257.

Style - Harvard Anglia:

Valishvili, T. \& Valishvili, T., 2014. Implementation of the method of problem-based learning at Akaki Tsereteli State University. MEST Journal, 15 07, 2(2), pp. 251-257.

Style - ISO 690 Numerical Reference:

Implementation of the method of problem-based learning at Akaki Tsereteli State University. Valishvili, Tamara and Valishvili, Tea. [ed.] Zoran Čekerevac. 2, Belgrade : MESTE, 07 15, 2014, MEST Journal, Vol. 2, pp. 251-257. 